\title{
Histopathological and cytological spectrum of lymphadenopathy: a window to preliminary diagnosis
}

\author{
Goyal $\mathbf{S}^{1}$, Brar RK ${ }^{2}$, Sehgal $\mathbf{S}^{3}$ \\ ${ }^{1}$ Dr Sona Goyal, Senior Resident, SMS Jaipur, India, ${ }^{2}$ Dr Rupinder Kaur Brar, Senior Resident/Tutor- Andaman \\ and Nicobar Islands Institute of Medical Sciences, Port Blair, India, ${ }^{3}$ Dr Sahil Sehgal, Junior Resident- \\ Andaman and Nicobar Islands Institute of Medical Sciences, Port Blair, India.
}

Address for Correspondence: Dr Rupinder Kaur Brar, Email: drrupinderbrar@gmail.com

\begin{abstract}
Introduction: Lymphadenopathy is a common clinical presentation of patients attending outdoor patient departments. The etiology varies with a wide spectrum ranging from inflammatory causes on one end to malignant on the other. In the present study, cytological and relevant histopathological diagnoses were done in 200 cases received in Department of Pathology. Aims and objectives: The present study aimed to find out the percentage of various lesions of lymph node and their prevalence according to age group and sex of patients. It also correlated the histo-cytodiagnosis in cases where both histology and cytology were available and compared the results of present study with similar other studies. Materials and Methods: This study was carried out in the department of pathology, Govt. medical college, Patiala. It included 200 cases of lymphadenopathies, either from Rajindra hospital or from health centers nearby. The cases were selected randomly. Lymph nodes included were of neck region, axilla, groin, from the extremities and the internal (mediastinal, abdominal and retroperitoneal). Apart from haematoxylin and eosin (H \& E) stain, special stains like Ziehl-Neelsen stain and giemsa stain were done wherever needed. Results: Out of 200 cases, 93 (46.5\%) cases were of reactive hyperplasia. Females were affected more commonly than males. Tuberculosis occurred more in younger patients whereas metastases were more common in older age group. Axillary lymph node was the most common lymph node involved. Conclusion: Histopathology gave accurate and confirmatory results than cytology. Lymph node evaluation is an integral part of patient management.
\end{abstract}

Keywords: Lymph node, Histopathology, Reactive hyperplasia

\section{Introduction}

Lymph node is a major anatomic component of the immune system [1,2]. Lymph nodes are clustered in small groups or chains at strategic locations, where they drain the lymphatic vessels of various anatomic regions. The drainage involves not only the mechanical filtration of the foreign bodies in the lymph but also the recognition and processing of antigens. Peripheral nodes are more numerous in younger than in older persons while they are absent in the newborns [3]. Surrounded by a connective tissue capsule, lymph node is composed of outer part known as cortex and inner medulla. Both cortex and medulla represent $\mathrm{B}$ zones and therefore associated with humoral types of immune

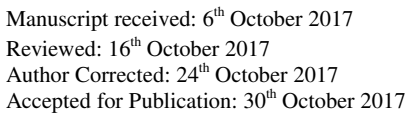


in the epitrochlear region a node as small as $0.5 \mathrm{~cm}$ becomes important. On the other hand, a node should be $>1.5 \mathrm{~cm}$ in the inguinal region to be considered as abnormal [8].

Superficial lymphadenopathy is a common finding and can be due to inflammation, metastatic malignancy or lymphoma [9]. Lymph nodes less than $1 \mathrm{~cm}$ in size are rarely malignant [10].

Lymph nodes are the most common site of metastatic malignancy and sometime constitute the first clinical manifestation of a disease [11,12,13]. Axillary and cervical lymph nodes are more likely to be informative in cases of generalized lymphadenopathy. Inguinal lymph nodes are to be avoided whenever possible because of the high frequency of chronic inflammatory and fibrotic changes present in them. Small superficial nodes may show only non-specific hyperplasia, whereas a deeper node of the same group may show diagnostic features [6]

Most enlarged lymph nodes are non-neoplastic and represent reaction to an infinite variety of antigens. In general, medical practice, neoplasia of lymph nodes is infrequent, about $1.1 \%$ of biopsies, whereas in referral centres their incidence may be as high as $60 \%[14,15,16]$.

In patients attending OPDs, reactive lymphoid hyperplasia is probably the most common diagnosis made [17]. The age of patients is one of the most important factors in determining the nature of enlarged lymph nodes. In children, most lymphadenopathies are benign, whereas in adults, the probability of malignancy increases with age [18].

Causes [19] of Lymphadenopathy can be nonneoplastic which include reactive lymphadenopathy due to rheumatoid arthritis, toxoplasmosis, early stages of infection with HIV, paracortical hyper plasia due to acute viral infections like infectious mononucleosis (IM), sinus histiocy tosis/ reticular hyperplasia due to chronic gastritis caused by Helicobacter pylori, rheumatoid arthritis and granulomatous lymphadenitis like tuberculosis, sarcoidosis.

The neoplastic causes include primary as NonHodgkin and Hodgkin disease while secondary as metastatic deposits. Other rare entities like silicone lymphadenopathy and dermatopathic lymphadenopathy have been described.

The present study was done to study neoplastic and non-neoplastic conditions of lymph nodes and their prevalence according to age group and sex, to correlate the histo cytodiagnosis in cases where both histology and cytology were available.

The importance of this study lies in the fact that FNAC findings are primary diagnostic tools in evaluation of enlarged lymph nodes and hence aid in the early diagnosis of the disease. This can be of utmost importance at the primary health care level. Lymph node biopsy plays an important role in typing of lymphoma and helps in cases, which cannot be diagnosed by FNAC [20].

\section{Material and methods}

This prospective study was carried out on 200 cases of lymphadenopathy in the Department of Pathology, Government Medical College, Patiala. The patients came to this department for FNAC from attached Rajindra hospital and TB \& chest diseases hospital.

Patients also came from Mata Kaushalya civil hospital and other health centres around Patiala. Excision biopsy samples of lymph nodes were received in $10 \%$ formalin.

The cases were selected randomly. It was taken into account that maximum cases with both cytological and histopathological examination were included. Age, sex, site of lymph node, duration of lymph node enlargement, history of fever and weight loss was noted.

The cases in which more than one group of lymph nodes were enlarged, were put under the site from which excision biopsy was taken. Patients who returned with recurrence of enlarged lymph nodes (defaulters in tuberculosis) were excluded from the study and were counted as a single case.

All relevant history, except the cytological diagnosis was provided during the examination of excision biopsy specimens, to remove any observer bias. Gross findings included size, colour, consistency and cut section (in excision biopsy). Special stains like Zeihl Neelsen and Giemsa stain were applied wherever needed. 


\section{Results}

Out of 200 cases of lymph nodes, 93 cases were of reactive etiology (46.5\%) and 23 cases of tuberculous lymphadenitis (11.5\%). Malignancy, both primary (7.0\%) and secondary (32.5\%) constituted 39.5\%. Rest of the $2.5 \%$ amounted to inconclusive sections. There were 14 cases $(7 \%)$ of primary malignancy and $65(32.5 \%)$ of metastatic deposits. In 5 cases $(2.5 \%)$, the diagnosis was inconclusive, only description was given (Table 1$)$.

Maximum number of females, $41(20.5 \%)$ were in the $4^{\text {th }}$ decade followed by $36(18 \%)$ in $5^{\text {th }}$ decade. Maximum number of males, $15(7.5 \%)$ were in the $2^{\text {nd }}$ decade and over 60 years of age followed by $10(5 \%)$ patients in $3^{\text {rd }}$ decade (Table 2).

Table-1: Histopathological diagnosis in 200 lymph node cases.

\begin{tabular}{|c|c|c|c|c|}
\hline \multicolumn{2}{|c|}{ Lesion } & No. Of cases & \multicolumn{2}{|c|}{$\%$ age } \\
\hline \multirow{2}{*}{$\begin{array}{l}\text { Non- neoplastic } \\
\qquad(n=116)\end{array}$} & Reactive & 93 & $46.5 \%$ & \multirow{2}{*}{$58 \%$} \\
\hline & Tuberculosis & 23 & $11.5 \%$ & \\
\hline \multicolumn{2}{|c|}{ Primary malignancy } & 14 & \multicolumn{2}{|c|}{$07.0 \%$} \\
\hline \multicolumn{2}{|c|}{ Metastatic } & 65 & \multicolumn{2}{|c|}{$32.5 \%$} \\
\hline \multicolumn{2}{|c|}{ Inconclusive } & 05 & \multicolumn{2}{|c|}{$02.5 \%$} \\
\hline \multicolumn{2}{|c|}{ Total } & 200 & \multicolumn{2}{|c|}{$100 \%$} \\
\hline
\end{tabular}

Table-2: Age and Sex wise distribution of 200 cases.

\begin{tabular}{|c|c|c|}
\hline Age (in yrs.) & Male (\%) & Female (\%) \\
\hline $0-10$ & $09(04.5)$ & $02(01)$ \\
\hline $11-20$ & $15(07.5)$ & $11(05.5)$ \\
\hline $21-30$ & $10(05)$ & $41(20.5)$ \\
\hline $31-40$ & $04(02)$ & $36(18)$ \\
\hline $41-50$ & $05(02.5)$ & $20(10)$ \\
\hline $51-60$ & $10(05)$ & $12(06)$ \\
\hline$>60$ yrs & $15(7.5)$ & $\mathbf{1 3 2}(\mathbf{6 6})$ \\
\hline Total & $\mathbf{6 8}(\mathbf{3 4})$ & \\
\hline
\end{tabular}

Table-3: Cytological and histopathological correlation.

\begin{tabular}{|c|c|c|c|c|c|}
\hline \multirow{2}{*}{$\begin{array}{l}\text { Histopathological } \\
\text { diagnosis with no of } \\
\text { cases }\end{array}$} & \multicolumn{5}{|c|}{ Cytological diagnosis } \\
\hline & Reactive & Tubercular & Lymphoma & Mets(SCC) & Mets(ADENO) \\
\hline Reactive, 32 & 32 & & & & \\
\hline $\mathrm{TB}, 17$ & & 17 & & & \\
\hline Lymphoma,07 & 01 & 01 & 05 & & \\
\hline Met(ADENO),04 & 01 & & & & 03 \\
\hline $\operatorname{Met}(\mathrm{SCC}), 06$ & & & & 06 & \\
\hline Total, 66 & 34 & 18 & 05 & 06 & 03 \\
\hline
\end{tabular}


Table-4: Site wise distribution of lymph node.

\begin{tabular}{|c|c|c|}
\hline Site & No. of cases & Percentage (\%) \\
\hline Axillary & 77 & 38.5 \\
\hline Cervical & 39 & 19.5 \\
\hline Mesenteric & 28 & 14 \\
\hline Inguinal & 13 & 06.5 \\
\hline Gall bladder & 07 & 03.5 \\
\hline Posterior auricular & 05 & 02.5 \\
\hline Submandibular & 05 & 02.5 \\
\hline Supraclavicular & 04 & 02 \\
\hline Submental & 04 & 02 \\
\hline Iliac & 03 & 01.5 \\
\hline Appendicular & 02 & 01 \\
\hline Gastric & 02 & 01 \\
\hline Pre tracheal & 02 & 01 \\
\hline Omental & 02 & 01 \\
\hline Infra clavicular & 01 & 0.5 \\
\hline Jugulo diagastric & 01 & 0.5 \\
\hline Generalized & 01 & 0.5 \\
\hline Para aortic & 01 & 0.5 \\
\hline Sapheno femoral & 01 & 0.5 \\
\hline Testicular & 01 & 0.5 \\
\hline Posterior triangle neck & 01 & 0.5 \\
\hline & & \\
\hline & & \\
\hline & 02 & \\
\hline & 01 & \\
\hline & 01 & 0.5 \\
\hline
\end{tabular}

Out of 34 cases diagnosed as reactive on histopathological examination, all the cases were found reactive on cytological examination and similar in tuberculous lesions also but in case of lymphoma, 2 cases were benign on cytological examination. In case of metastatic malignancy, 1 case was benign on cytological examination (Table 3). Out of 200 cases, 77 (38.5\%) cases presented with axillary lymph node enlargement, 39 (19.5\%) with cervical node, 28 (14\%) with mesenteric node, 13 (6.5\%) with inguinal lymph node, rest of the cases with other nodal enlargement (Table 4).

\section{Discussion}

The present study comprised of 200 cases of lymphadenopathy referred to the department of pathology, Government Medical College, Patiala. The results of histolopathology and cytological findings were compiled, scrutinized and compared with other studies. Out of total 200 cases, 68 were males and 132 were females, revealing a female preponderance with female to male ratio of 1.9:1. The age of patients ranged from 4years to 100 years. The study conducted by Dandapat et al (1990) had a ratio of 1.2:1 [21] while Shrestha et al (2007) reported a female to male sex ratio of 1.04:1, also showing female preponderance [22]. The study conducted by Lee B et al (1999) reported a ratio of 1.5:1 [23]. In the present study, age ranged from 4 to 100 years with mean of 40.9 years. In the study of Dandapat et al, the age ranged from 1-65 years with the mean of 33 years.

In our study, out of 200 cases of lymph nodes, $116(58 \%)$ cases were classified as benign, 79 (39.5\%) cases as malignant and $5(2.5 \%)$ cases were inadequate. Out of 116 cases of benign, $93(46.5 \%)$ cases were reactive and $23(11.5 \%)$ cases were of tubercular etiology. Out of 79 cases, 14 cases i.e., $7 \%$ were of primary malignancy and 65 i.e., 32.5\% were of metastatic deposits. The most common cause of lymph node enlargement in all studies was reactive hyperplasia. In a study conducted by Zahir et al (2009) the most common cause of lymph node enlargement was reactive hyperplasia followed by malignancy than infectious disease [24]. In a study by 
Original Research Article

Thomas et al (1995), most common cause was reactive hyperplasia followed by granulomatous pathology than malignancy [25]. Out of 200 cases, the most common lymph node involved was axillary in 77 cases $(38.5 \%)$ followed by 39 cases of cervical lymph node (19.5\%) and 28 cases of mesenteric lymph node (14\%) along with 13 cases inguinal lymph node. The most common lymph node involved was axillary which was in concordance with previous studies conducted by Ojo et al (2005) [26] and Lee B et al (1999) [7]. In present study metastatic deposits were most common cause for axillary lymph node enlargement. Also Lee B et al and Ojo et al showed the same results.

In the present study, age ranged from 4 to 100 years, in the study of Hirachand et al (2009) [27], age ranged from 3-85 years, in the study of Shaikh et al (2010) [28], age ranged from 10-70 years, in the study of Dandapat age ranged from 1-65 years.

In the present study $39.5 \%$ cases were found as neoplastic lesions, which constitute both primary malignancy as well as metastatic malignancy. In study conducted by Shaikh et al (2010), 20\% cases were of neoplastic etiology. In study conducted by Olu-Eddo et al (2006) [29], 20\% cases were of neoplastic etiology. The result of present study was analyzed and compared with other studies. Hodgkin's and Non-Hodgkin's lymphoma are the primary malignancy of lymph nodes. Hodgkin's lymphoma was originally described by Thomas Hodgkin in 1832 [30] and characteristic Reed-Sternberg cell are present in this type. Classical Hodgkin lymphoma, because of its variable cellularity, can resemble various reactive lymphadenopathies and other lymphomas [31,32].
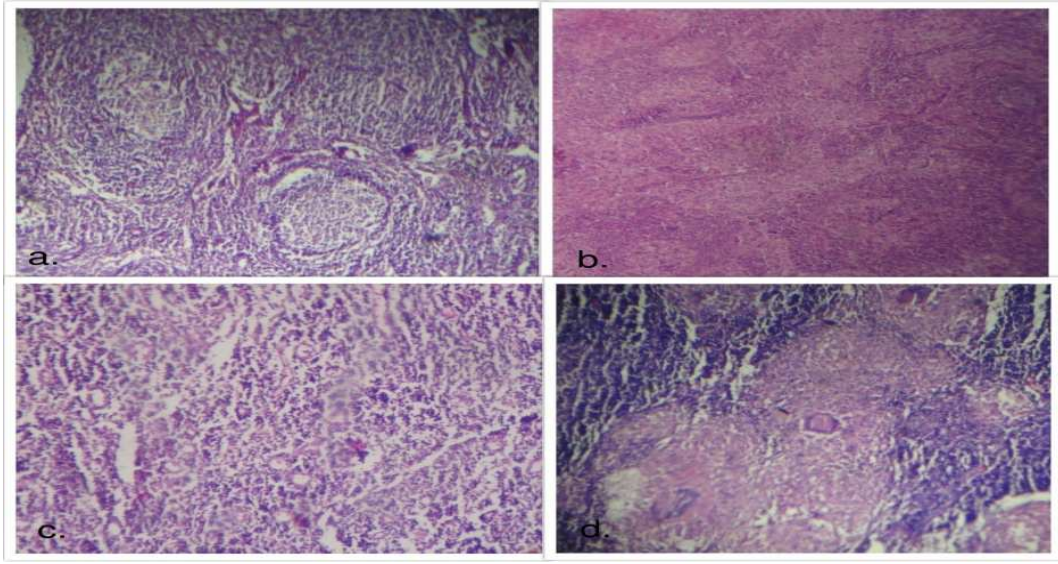

Figure-1: a) Follicular hyperplasia (H \& E, 400X), b) Sinus hyperplasia (H \& E, 400X), c) Paracortical hyperplasia (H \& E, 400X), d) Granulomas in lymph node (H\&E, 400X)
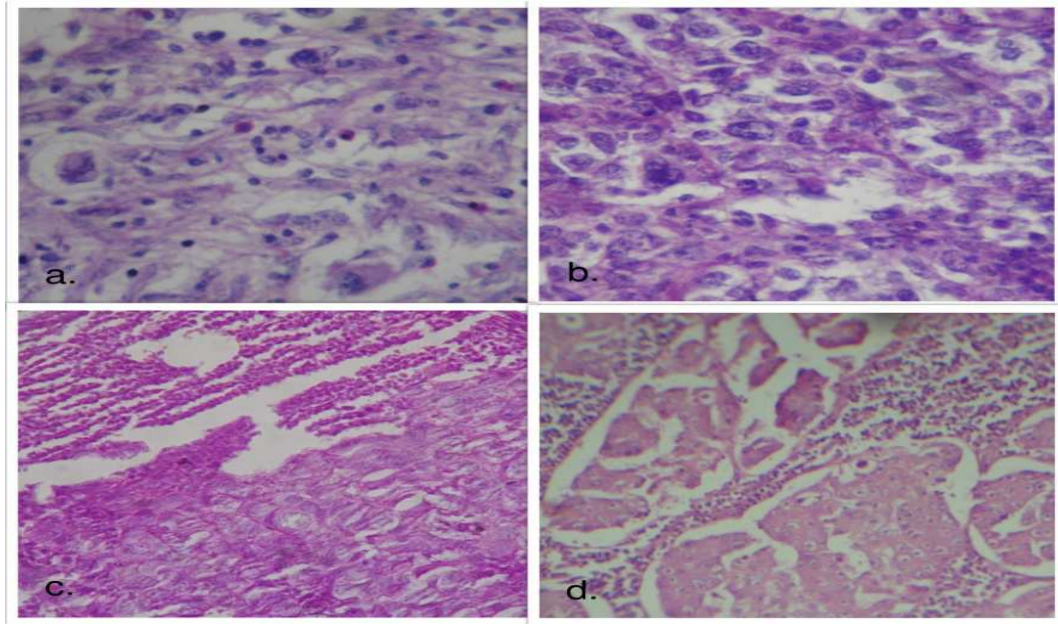

Figure-2: a) Hodgkin's Lymphoma (H \& E, 400X), b) Non-Hodgkin's Lymphoma, Large cell type (H \& E, 400X), c) Adenocarcinomatous secondaries (H \& E, 400X), d) Squamous Cell Carcinoma secondaries (H \& E, 400X). 
Granulocyte-rich cases of classical Hodgkin lymphoma can resemble suppurative lymphadenitis or neutrophilrich anaplastic large-cell lymphoma [33]. Histiocyte-rich cases can resemble granulomatous disorders. ReedSternberg like cells that occur in some reactive lymphadenopathies such as infectious mononucleosis, as well as in non-Hodgkin lymphomas, can be problematic for diagnosis [34]. Cases of classical Hodgkin lymphoma with many neoplastic cells, such as the syncytial variant of nodular sclerosis type, can resemble large B-cell lymphoma or anaplastic large-cell lymphoma.

Classical Hodgkin lymphoma can also resemble T-cell / histiocyte-rich large B-cell lymphoma or peripheral Tcell lymphoma [35]. For these reasons, fine needle aspiration cytology (FNAC) is considered less accurate for the diagnosis of Hodgkin lymphoma than it is for non-Hodgkin lymphoma [36].

Cytology was available in 66 cases for correlation. The comparison of present study with Dhingra [37] and Hirachand was done. In the present study 116 cases were placed in benign category with cytology available in 52 cases, out of which 3 cases were proved to be malignant on histopathology. Thereby making the accuracy in diagnosing benign lesions to be $+6 \%$. Dhingra described that out of 80 cases labeled as benign on cytology, 2 cases turned out as malignant on histopathology examination giving an accuracy of $+2 \%$. Hirachand described that out of 48 cases of benign on cytology examination, 45 cases were benign on histopathology giving an accuracy of $+6 \%$. In the present study 34 cases were of Non-specific lymphadenitis on cytological examination. Out of these 32 cases were confirmed as non-specific lymphadenitis on histopathology giving an accuracy of $+6 \%$. 18 cases were of Tuberculosis on cytology, out of these 17 cases were confirmed as Tuberculosis on histopathology giving an accuracy of $+5 \%$. In the present study 79 cases were placed in malignant category with cytology available in 14 cases. All cases were malignant on histopathology giving an accuracy of $100 \%$. Dhingra described that out of 10 cases labeled as malignant on cytology, 9 turned out as malignant on histopathology giving an accuracy of $+11 \%$. Hirachand described that 24 cases were malignant on cytology when compared with histopathology 22 cases turned out as malignant giving an accuracy of $+9 \%$. In the present study, 5 cases were of Primary Malignancy on cytological examination. All of these 5 cases were confirmed as Primary Malignancy on histopathology giving an accuracy of $100 \%$. 9 cases of metastatic malignancy were present on cytology. All of these 9 cases were confirmed as metastatic malignant on histopathology giving an accuracy of $100 \%$ (Table 3 ).

\section{Conclusion}

It was concluded from the present study that histopathology gave definitive diagnosis as compared to cytology. Lymphadenopathy is a common clinical presentation with $>50 \%$ cases being benign. Females were affected more commonly than males. In the present study, female to male ratio was 1.9:1. Tuberculosis being more common in younger age group warrants the need for definite treatment and management process.

Metastases, particularly adenocarcinomatous deposits are more common in elderly age group. Simple examination of lymph node cytology/ histopathology can help in clinical diagnosis of many cases.

\section{Abbreviations}

FNAC: Fine needle aspiration cytology, HIV: Human immunodeficiency virus, TB: Tuberculosis, WHO: World health organization, IM: Infectious mononucleosis, H\&E: Haematoxylin \& Eosin.

\section{Funding: Nil, Conflict of interest: None Permission of IRB: Yes}

\section{References}

1. Delves PJ, Roitt IM. The immune system. First of two parts. N Engl J Med. 2000; 343:37-49. DOI: 10. 1056/ NEJM 200010123431520.

2. Van der valk P, Meijer CJLM. Lymph nodes. In Mills SE: Histology for pathologists. $3^{\text {rd }}$ ed. Philadelphia: Lippincott Williams and Wilkins; 2007; p. 763-82.

3. Cottier H, Turk J, Sobin L. A proposal for a standardized system of reporting human lymph node morphology in relation to immunological function. Bull World Health Organ. 1972; 47(3): 375-417.

4.Stein H, Bonk A, Tolksdor f G, Lennert K, Rodt $\mathrm{H}$, Gerdes J. Immunohistologic analysis of the organization of normal lymphoid tissue and non- 
Hodgkin's lymphomas. J Histochem Cytochem. 1980 Aug; 28(8):746-60.

5. Eroschenko VP. diFiore's atlas of histology with functional correlations, $11^{\text {th }}$ ed. New Delhi: Wolters Kluwer; 2009: 196-97.

6. Rosai J, Ackerman. Rosai and Ackerman's Surgical Pathology. $9^{\text {th }}$ ed. New Delhi: Elsevier; 2004; p.1772, 1879, 974.

7. Roitt IM. Essential immunology. $9^{\text {th }}$ ed. London: Blackwell Publishing Company; 1997. Chapter 2, Specific acquired response; p.152-67.

8. Alice R, Bruce C. The lymphatic system. In Waldo Nelson, Behraman RE, Kleigman eds. Textbook of Pediatrics. $16^{\text {th }}$ ed. Philadelphia: W.B. Saunders; p.1527-29.

9. Linet OI, Metzler C. Practical ENT. Incidence of palpable cervical nodes in adults. Postgrad Med. 1977 Oct;62(4):210-3.

10. Pangalis GA, Vassilakopoulos TP, Boussiotis VA, Fessas P. Clinical approach to lymphadenopathy. Semin Oncol. 1993 Dec;20(6):570-82.

11. Didlolker MS, Fanous N, Elias EG. Metastatic carcinomas from occult primary tumours. A study of 254 patients. Ann Surg. 1977; 186: 628-30.

12. Haagensen CD, Feind CR, Herter FP, Slanetz CA JR, Weinberg JA. The lymphatics in cancer. Philadelphia: W.B. Saunders; 1972.

13. Willis RA. The spread of tumours in the human body, $3^{\text {rd }}$ ed. Stoneham: Butterworth; 1973.

14. Fijten GH, Blijham GH. Unexplained lymphadenopathy in family Practice-an evaluation of the probability of malignant causes and the effectiveness of physicians' workup. J Fam Pract.1988 Oct; 27(4): 373-76.

15. Ferrer R. Lymphadenopathy: Differential diagnosis and Evaluation. American Family Physician. 1998 Oct 15; 58:1313-20.

16. Bazemore AW, Smucker DR. Lymphadenopathy and malignancy. American Family Physician. 2002 Dec 1; 66(11): 2103-10.
17. Ioachim HL, Medeiros LJ. Ioachim's lymph node pathology, $4^{\text {th }}$ ed. Philadelphia: Lippincott Williams and Wilkins; 2008.

18. Habermann TM, Steensma DP. Lymphadenopathy. Mayo Clin Proc. 2000 Jul; 75 (7): 723-32.

19. Koss LG, Melamed MR. Diagnostic cytology and its histologic basis. $5^{\text {th }}$ ed. Phildelphia: Lippincott Company; 2006.

20. Abdullah P, Mubarik A, Zahir N. The importance of lymph node biopsy in diagnosis of lymphadenopathy. J Coll Physicians Surg Pak 2000; 10(8): 298-301.

21. Dandapat MC, Mishra BM, Dash SP, Kar PK. Peripheral lymph node tuberculosis: a review of 80 cases. Br J Surg. 1990 Aug;77(8):911-2.

22. Shrestha AK, Chalise PR, Shrestha ML. Lymph node biopsies- A Hospital based retrospective study. J Nepal Med Assoc 2009; 48(176):306-9. PMCID: PMC3993046

23. Lee B, Chang L. Fine Needle Aspiration Biopsy and Histopathologic Diagnosis in the Head and Neck Masses. Korean J Otolaryngol- Head Neck Surg. 1999 Nov; 42(11): 1429-34.

24. Zahir ST, Azimi A. Histopathologic findings of lymph node biopsy cases in comparison with clinical features. Pak J Med Sci. 2009; 25(5): 72833. ISSN 1681-715X

25. Thomas JO, Ladipo JK, Yawe T. Histopathology of lymphadenopathy in a tropical country. East Afr Med J. 1995 Nov;72(11): 703-5.

26. Ojo BA, Buhari MO, Malami SA, Abdulrahaman MB. Surgical lymph node biopsies in University of Ilorin Teaching Hospital, Ilorin, Nigeria. Niger Postgrad Med J. 2005 Dec; 12(4): 299-304. PMID: 16380743.

27. Hirachand S, Lakhey M, Akhter J, Thapa B. Evaluation of fine needle aspiration cytology of lymph nodes in Kathmandu Medical College, Teaching hospital. Kathmandu Univ Med J (KUMJ). 2009 Apr-Jun;7(26):139-42. 
28. Shaikh MS, Baloch I, Bhatti Y. An audit of 200 cases of cervical Lymphadenopathy. Medical Channel. 2010 Jan-Mar; 16: 85-7.

29. Olu-Eddo AN, Ohanaka CE. Peripheral lymphadenopathy in Nigerian adults. J Pak Med Assoc. 2006 sept; 56(9): 405-8. www.jpma. org.pk /PdfDownload/837.pdf

30. Bonadonna G. Historical review of Hodgkin's disease. Br J Haematol. 2000; 110: 504-511. DOI: 10.1046/j.1365-2141.2000.02197.x

31. Kardos TF, Vinson JH, Behm FG, Frable WJ, O'Dowd GJ. Hodgkin's disease: diagnosis by fineneedle aspiration biopsy. Analysis of cytologic criteria from a selected series. Am J Clin Pathol. 1986 Sep;86(3):286-91.

32. Jimenez-Heffernan JA, Vicandi, Lopez-Ferrer $\mathrm{P}$. Value of the fine needle aspiration cytology in the initial diagnosis of Hodgkin's disease: analysis of 188 cases with an emphasis on diagnostic pitfalls. Acta Cytol. 2001; 45(3): 300-06. PMID: 11393058

33. Tani E, Ersoz C, Svedmyr E. Fine-needle aspiration cytology and immunocytochemistry of
Hodgkin's disease, suppurative type. Diagn cytopatho. 1998; 18(1): 1-4.

34. Iacobuzio-Donahue CA, Clark DP, Ali SZ. Reed-Sternberg-like cells in lymph node aspirates in the absence of Hodgkin's disease: pathologic significance and differential diagnosis. Diagn Cytopatho. 2002 Dec; 27(6): 335-39.

35.Vezzoli P, Fiorani R, Girgenti V, Fanoni D, Tavecchio S, Balice Y, Mozzana R, Crosti C, Berti E. Cutaneous T-cell/ histiocyte- rich B-cell lymphoma: a case report and review of the literature. Dermatology. 2011;222(3):225-30. doi: 10. 1159/ 000327376. Epub 2011 Apr 30.

36. Volmar KE, Singh HK, Gong JZ. The advantages and limitations of the role of core needle and FNA biopsy of lymph nodes in the modern era: Hodgkin and non-Hodgkin Lymphomas and metastatic Disease. Pathology Case Reviews. 2007; 12 (1): 10-26. DOI: 10.1097 /01. pcr.0000252857.12872.52

37. Dhingra V, Misra V, Mishra R, Bhatia R, Singhal M. Fine needle aspiration cytology as a diagnostic tool in pediatric lymphadenopathy. Journal of Clinical and Diagnostic Research 2010 June; 4: 2452-57.

\section{How to cite this article?}

Goyal S, Brar RK, Sehgal S. Histopathological and cytological spectrum of lymphadenopathy: a window to preliminary diagnosis. Int J Med Res Rev 2017;5(10):900-907.doi:10.17511/ijmrr. 2017.i10.05 